\title{
Design of Feeder Route Network Using Combined Genetic Algorithm and Specialized Repair Heuristic
}

Prabhat Shrivastava, Sardar Patel College of Engineering, Andheri, India Margaret O'Mahony, Trinity College, Dublin, Ireland

\begin{abstract}
In metropolitan cities an efficient integrated public transportation system is unavoidable to restrict unsustainable growth of private and intermediate transport modes. Well-designed feeder routes and coordinated schedules to minimize transfer time from the main transit to feeder buses play an important role. Past literature reveals that a heuristic approach had been popular for design of routes and had been applied successfully in a variety of network design problems. Nontraditional optimization techniques, especially genetic algorithms, are also found to be very effective in the generation of optimized feeder routes and schedules. In this research the genetic algorithm first develops feeder routes and then a specialized heuristic algorithm works as a repair algorithm to satisfy the demand of all the nodes. Thus, the advantages of both genetic algorithms and specialized heuristic algorithms are obtained in this method. The developed feeder route structure is found to be better in terms of load factors in buses, satisfaction of demand, and waiting time for feeder buses as compared to existing scenarios and earlier approaches adopted for the same study area.
\end{abstract}




\section{Introduction}

In metropolitan cities of developed and developing countries, suburban railway and public buses are the most common public transport carriers. Commuter dissatisfaction toward public transport stems from increased travel time, poor levels of comfort, uneconomical operations, and higher out-of-vehicle time, especially at transfer points. These problems can be solved by appropriate coordination between major public transport modes. Successful coordination implies

- the traveller's ability to transfer freely and conveniently between modes;

- distinct service areas between each modes, thereby minimizing duplication of services;

- adjustment and interrelationship of schedules; and

- joint fare structure.

A poorly coordinated transfer can require long, irregular waiting for infrequent connecting services. The point of balance between travellers' demand for a direct service and the transit operator's need for economy often lies in the level of attention given to the details of the transfer. Thus, well-designed feeder routes satisfying maximum demand with acceptable travel times are of prime concern. To minimize transfer time, coordinated schedules have to be optimized.

\section{Literature Review and Objective of Study}

Many research studies have been conducted of bus route network design problems involving development of routes and schedules. Lampkin and Saalmans (1967), Silman et al. (1974), Dubois et al. (1979), Mandl (1980), and Baaj and Mahmassani (1995) developed bus routes using a heuristic approach. Shrivastava and Dhingra (2001) successfully implemented a heuristic approach for the design of feeder routes for feeder public buses at suburban railway stations. Heuristic algorithms are not theoretically rigorous but have been used successfully for real networks and are capable of providing suboptimal values. Genetic algorithms (GAs), which are robust optimization techniques, have been used successfully for routing and scheduling problems. Pattnaik et al. (1998), Gundaliya et al. (2000), and Tom and Mohan (2003) used GAs for the design of bus route networks. Shrivastava and Dhingra (2002) successfully generated coordinated schedules of public buses for existing schedules of suburban trains on the developed feeder route network using GAs. Chien et al. (2003) presented a model for optimizing service headway and 
a bus route serving an area with a commuter (many-to-one) travel pattern. The bus route is optimized by minimizing total system cost, including operator and user costs, while considering diagonal links in the study network. Zhao and Ubaka (2004) presented a mathematical methodology for transit route network optimization. The goal was to develop an effective computational tool for the optimization of large-scale transit route networks. The objectives were to minimize transfers and optimize route directness while maximizing service coverage. Agrawal and Mathew (2004) proposed two parallel genetic algorithm (PGA) models. The first was a global parallel virtual machine (PVM) parallel GA model. The second was a global message passing interface (MPI) parallel GA model. The global PVM model appeared to perform better than the other. Fan and Machemehl (2004) formulated a multiobjective nonlinear mixed integer model for a transit route network design problem (TRNDP). The proposed solution framework consisted of three main components: an Initial Candidate Route Set Generation Procedure (ICRSGP); a network analysis procedure; and a Heuristic Search Procedure (HSP). Five heuristic algorithms-including the GA, local search, simulated annealing, random search, and tabu search - are solution methods for finding an optimal set of routes from the huge solution space. Sensitivity analysis for each algorithm was conducted and model comparisons were performed.

Studies on the development of feeder routes for the same study area using different approaches have been presented. In one study, Shrivastava and O'Mahony (2005) developed feeder routes using a heuristic algorithm that was found to be very effective and the demand at all nodes was satisfied by the developed set of routes. Using a heuristic approach, a set of the routes cannot be guaranteed to be at optimal level; it may yield suboptimal results also. In other research, Shrivastava and O'Mahony (2006) developed feeder routes and schedules simultaneously using GAs for the same study area. While the developed routes and schedules were optimum, the entire demand was not satisfied because in a typical study area some of the nodes did not have good connectivity with other nodes. In view of this, instead of 17 nodes only 16 were selected; the remotest node in the study area was not included. In this article, both approaches are combined and the benefits of both are obtained. The optimal set of feeder routes are first developed by GAs and if any demand remains unsatisfied, it is inserted and/or attached to the best possible route by the specialized heuristic approach, which works as a repair algorithm. Thus, the advantages of both approaches are achieved in this research. 
The objective of the proposed research is development of a feeder bus route network and coordinated schedules for public buses for the existing schedules of main transit (suburban train) at the given Dublin (Ireland) Area Rapid Transit (DART) station. To satisfy the entire demand, the routes developed by GAs were modified by a well-designed heuristic approach. The modified routes were used for determination of coordinated schedules. The Dun Laoghaire DART station was selected as the case study. Dun Laoghaire is a rapidly growing suburb of Dublin. Coordination between DART services and Dublin public buses for this DART station is attempted.

\section{Data Collection}

DART is a suburban railway system in Dublin running along the coastline of Dublin Bay from Greystones to Howth and Malahide. The existing DART line has 32 stations. Lack of coordination between public buses and DART services has been observed even during peak hours at many stations. Dun Laoghaire is one of the prominent DART stations from where large numbers of trips originate. Dun Laoghaire was selected as the study area due to its land-use pattern, which allows greater scope of feeder bus services from the station. Considerable movement of commuters takes place to many areas from the DART station.

Typical traffic surveys were conducted during the morning peak period (i.e., 7-9AM) on April 28, 2004. Since the maximum number of commuters travel from 8-9AM, this time period is identified as the peak hour. It was confirmed during the surveys that after 9AM commuter traffic starts decreasing and becomes much less after 9.30AM. During the surveys, commuters exiting the DART station were counted manually. Traffic surveyors conducted sample interviews with commuters leaving the DART station. Commuters were asked about their destinations, mode of transport, and travel time to their destinations from the DART station. Commuters not opting for public buses for their further journeys were also asked about their willingness to shift to public buses if buses were coordinated with DART services in future. Of those surveyed, 40 percent work very near the DART station and they only have to walk about 5 minutes. These commuters were not interested in shifting to public buses even if they are well coordinated with DART services. The percentage of commuters willing to move to public buses was added to those who use public buses and a potential demand matrix for public buses was developed. There are 16 destinations (nodes) for which demand exists from the DART station. Table 1 indicates potential demands to various destinations. It 
was also observed during the surveys that in the morning peak period the trains toward the city center (northbound trains) contribute about 30 percent of the passengers; the remaining 70 percent were by trains from the city center (southbound trains). There were nine northbound and eight southbound trains during the peak hour of 8-9AM. The schedule coordination for feeder buses is attempted for theses trains during the indicated peak hour.

Table 1. Potential Demand to Various Destinations

\begin{tabular}{|c|l|c|c|c|}
\hline \multirow{2}{*}{$\begin{array}{c}\text { Node No. } \\
\text { (code) }\end{array}$} & \multicolumn{1}{|c|}{ Destinations } & \multicolumn{3}{|c|}{ Potential Demand to Various Destinations } \\
\cline { 3 - 5 } & & $\mathbf{7 - 8 A M}$ & $\mathbf{8 - 9} \boldsymbol{A M}$ & $\mathbf{7 - 9} \boldsymbol{A M}$ \\
\hline 1 & Dun Laoghaire DART Station & 00 & 00 & 00 \\
\hline 2 & Dun Laoghaire College & 39 & 202 & 241 \\
\hline 3 & Sallynoggin & 17 & 103 & 120 \\
\hline 4 & Monks town & 10 & 63 & 73 \\
\hline 5 & Deans Grange & 16 & 93 & 109 \\
\hline 6 & Temple Hill & 02 & 06 & 08 \\
\hline 7 & Black Rock & 08 & 46 & 54 \\
\hline 8 & Stillorgan & 13 & 77 & 90 \\
\hline 9 & Leopards town & 02 & 08 & 10 \\
\hline 10 & Foxrock & 02 & 08 & 10 \\
\hline 11 & Maple Manor/Cabinteely & 02 & 04 & 06 \\
\hline 12 & Lough Linstown & 13 & 78 & 91 \\
\hline 13 & Mount Merrion & 02 & 15 & 17 \\
\hline 14 & University College of Dublin & 04 & 23 & 27 \\
\hline 15 & Dundrum & 06 & 31 & 37 \\
\hline 16 & Sandyford & 03 & 15 & 18 \\
\hline 17 & Rouches Town Avenue & 02 & 04 & 06 \\
\hline
\end{tabular}

\section{Proposed Methodology}

The overall methodology for development of feeder routes and coordinated schedules is presented in Figure 1. The methodology is explained in the following steps. 


\section{Figure 1. Methodology for Development of Feeder Routes and Coodinated Schedules}

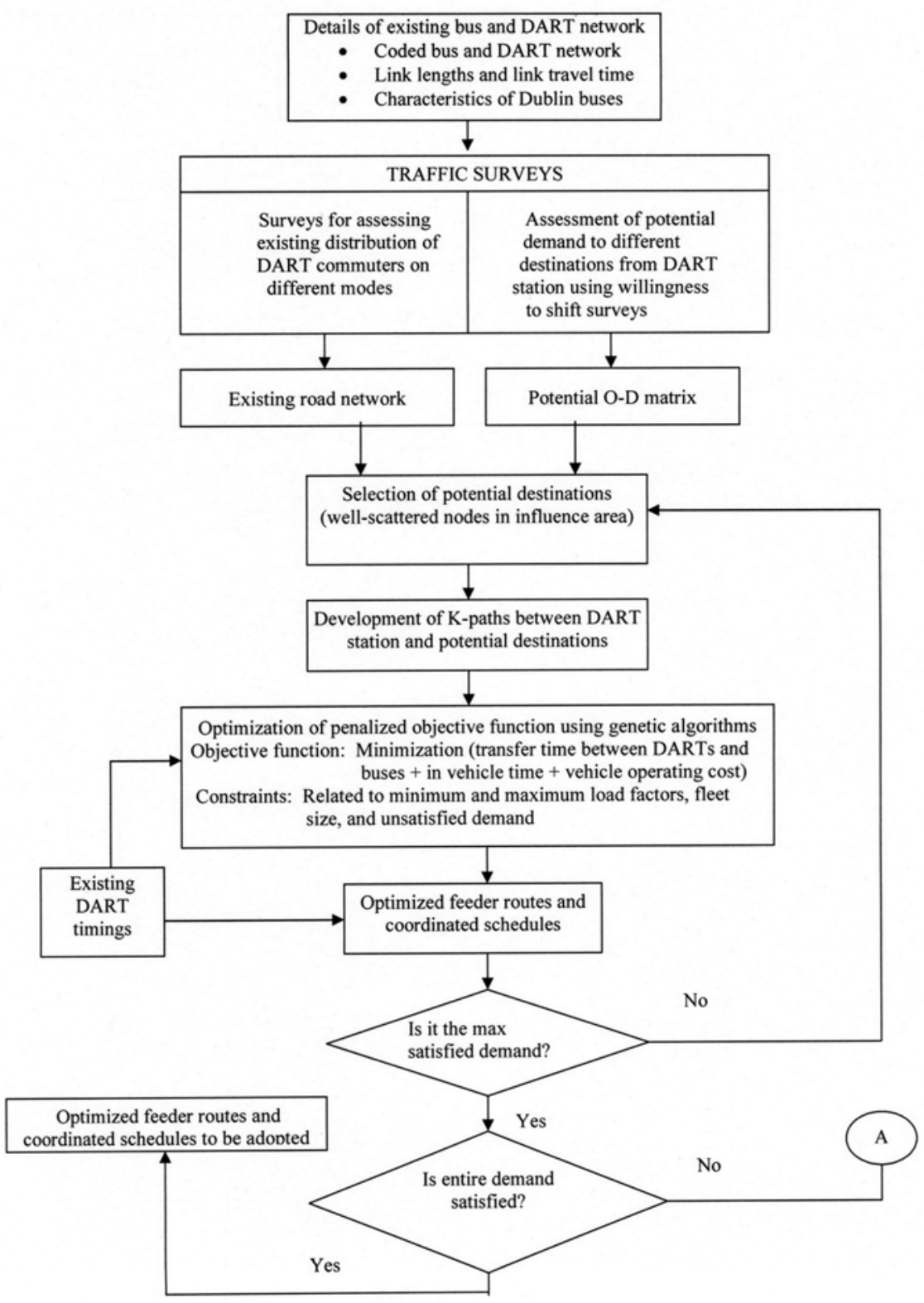




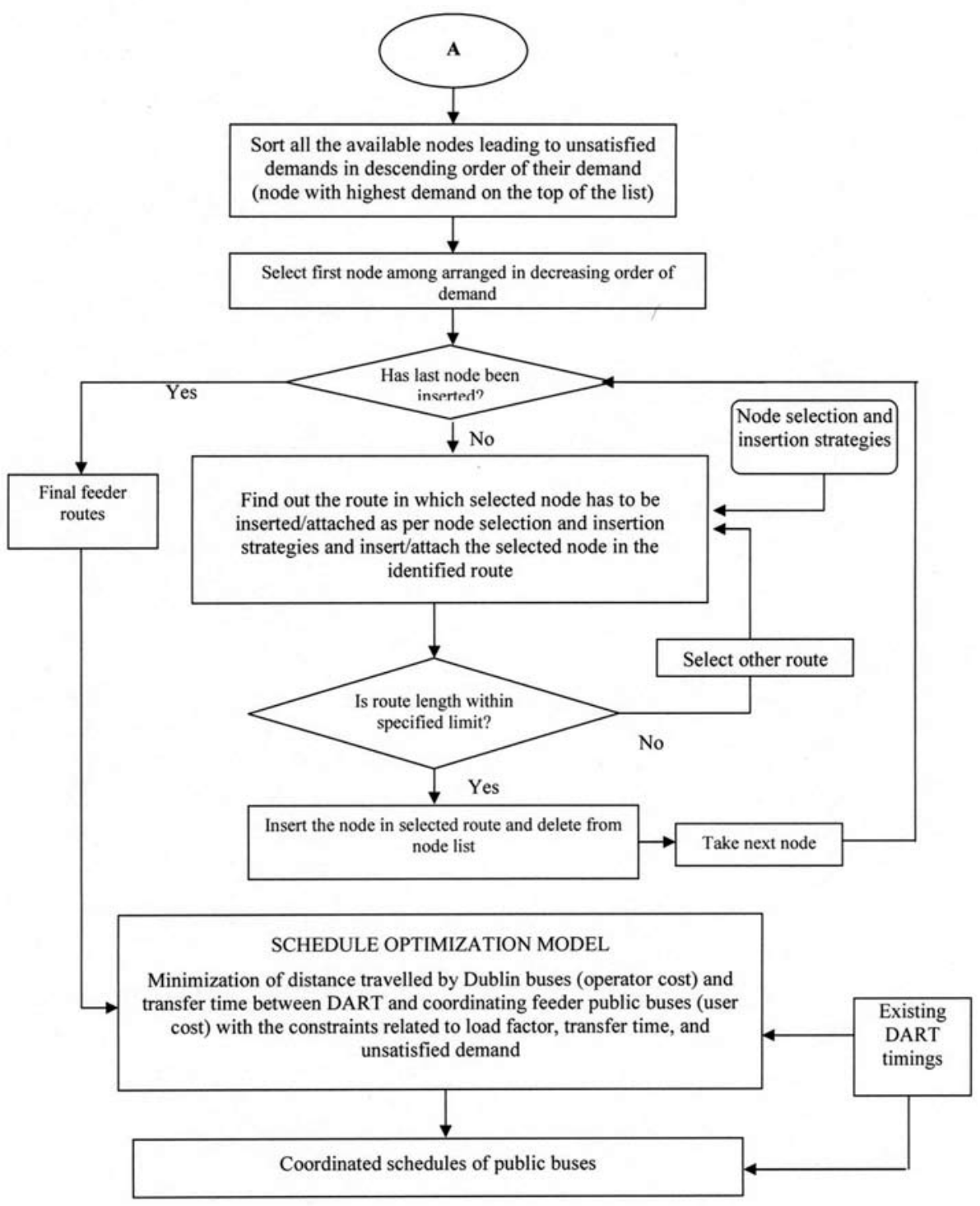




\section{Step 1}

A potential demand matrix is developed with its origin at a DART station and with destinations as identified in traffic surveys.

\section{Step 2}

A travel distance matrix and connectivity details between various nodes were obtained from the Dublin Street Map (2000). The travel distance matrix was converted into a travel time matrix in "minutes," using an average speed of $15 \mathrm{Km} / \mathrm{hr}$ to address the existing congestion level and road geometrics of the influence area (Wilson 2000).

\section{Step 3}

Other parameters like capacity of buses, minimum and maximum load factors, maximum fleet size, minimum frequency per hour, minimum and maximum lengths of routes, and multiplying constants, which have been used to convert objective function into monetary values of "euro," were decided as per practical realities and existing conditions.

\section{Step 4}

Using the k-path algorithm (Eppstein 1994), k-shortest paths were developed between the DART station and a set of destinations, which are well scattered and cover the entire influence area. The value of $K$ is adopted as 5 for the case study.

In this research, destinations were based on their locations so that a larger portion of the feeder route network is optimized by GA and the repair heuristic is used only for a few nodes. In view of this, various sets of destinations that were located away from origin and well scattered in the influence area were selected. The set of destinations was selected for which maximum demand is satisfied with the least number of $k$-paths using GA and few node/nodes are left for the repair heuristic.

With the help of traffic surveys, various locations (nodes) to which demand existed were identified. The selected set of nodes, based on the above criteria for which $\mathrm{k}$-paths were developed, is identified as potential destinations.

$\mathrm{K}$ indicates the number of short paths that can be developed between a given origin (DART station) and potential destination. These short paths are developed in the increasing order of their lengths. In this research, the value of $k$ is selected as 5 (i.e., between each origin-DART Station) and potential destination. Five short paths are developed, of which the first is the smallest and the last is largest. Out of 
these k-paths the best one is selected after application of GA (corresponding to optimized penalized objective function).

\section{Step 5}

The program to calculate a penalized objective function (summation of objective function and penalties due to violation of constraints) is developed in $\mathrm{C}++$ environment. The set of $\mathrm{k}$-paths ( 5 in the case study for each origin and potential destination) are used with the GA. The coding of a path and its corresponding frequencies are done together in one string only. The binary digit coding to represent routes and schedules together has been adopted. The set of $k$-paths and frequencies for which the objective function along with penalties is minimum is selected as optimized routes and frequencies. These routes are used for application of specialized heuristics discussed in further steps. The frequencies are used to derive coordinated schedules for the existing DART schedules. Details of the objective function, penalties, and application of GAs are discussed below.

Details of Objective Function, Penalties and Use of GAs. The objective function is adopted as minimization of user and operator costs. User cost is the summation of in-vehicle time cost and transfer time cost between DARTs and buses. Operator cost is associated with vehicle operation cost. Constraints are related to load factor, fleet size, and unsatisfied demand. Mathematically, the objective function and various constraints are as follows:

Objective Function.

Minimize total cost, $Z=\{$ Transfer time cost between DARTs and coordinating buses + travel time cost in buses on selected routes (in-vehicle time cost in buses) + vehicle operation cost (VOC) of Dublin buses\}

Mathematically it can be expressed as

Minimize

$$
\begin{aligned}
& \longleftarrow \text { Transfer time between } \mathrm{n}^{\text {th }} \text { and } \mathrm{s}^{\text {th }} \text { bound DARTs and buses (first term) } \longrightarrow \\
& \mathrm{C}_{1}\left\{\sum_{j} \sum_{u} \sum_{l} \operatorname{pass}_{\mathrm{j}}^{\mathrm{u}}\left(\operatorname{bus}_{\mathrm{j}}{ }^{1}-\operatorname{dart}^{\mathrm{u}}\right) \delta_{\mathrm{j}}^{\mathrm{u} \cdot 1}+\sum_{j} \sum_{u} \sum_{l} \operatorname{pass}_{\mathrm{j}}^{\mathrm{v}}\left(\operatorname{bus}_{\mathrm{j}}{ }^{1}-\operatorname{dart}^{\mathrm{y}}\right) \delta_{\mathrm{j}}^{\mathrm{v} \cdot 1}\right\}+
\end{aligned}
$$




$$
\begin{aligned}
& \leftarrow \underset{\text { in bus }\left(2^{\text {nd }} \text { term }\right)}{\text { In vehime time }} \rightarrow \underset{\left(3^{\text {rd }} \text { term }\right)}{\leftarrow \text { VOC } \rightarrow} \rightarrow \\
& \mathrm{C}_{2}\left\{\sum_{j} \operatorname{pass}_{\mathrm{j}} \times \mathrm{t}_{\text {inv } j}\right\}
\end{aligned}
$$

Constraints.

$\begin{array}{ll}\text { 1. } \frac{Q_{j \cdot \max }}{N_{j} \times C A P} \leq L \max & \text { Maximum load factor constraint } \\ \text { 2. } \frac{Q_{j \cdot \max }}{N_{j} \times C A P} \geq L_{\min } & \text { Minimum load factor constraint }\end{array}$

3. $\sum_{j \in S R} \mathrm{NB}_{\mathrm{j}}=\sum_{k \in S R} \frac{N j *(R T) j}{T P} \leq \mathrm{W}($ for all $\mathrm{j} \leq \mathrm{SR})$

Fleet size constraint

4. $\quad \sum_{j} d_{\text {unsat }}=0$

Unsatisfied demand constraint

Where:

$\mathrm{j} \quad$ is the number of routes available at each station (as per number of potential selected destinations)

1 equals the number of buses available for $\mathrm{u}^{\text {th }}$ northbound DART and $\mathrm{v}^{\text {th }}$ southbound DART

VOC represents vehicle operating cost for Dublin buses

$\mathrm{C}_{1} \quad$ is the cost of transfer time in Euro per minute, 11.32 cents/minute for the case study (Steer Davies 1994)

$\mathrm{C}_{2}$ equals the cost of in-vehicle time in Dublin buses, 0.076 cents/minute for the case study (Steer Davies 1994)

$\mathrm{C}_{3} \quad$ denotes the cost of operation of Dublin bus per Km., $€ 3.66$ for Dublin buses for the case study (Wilson 2000)

pass $_{\mathrm{j}}{ }^{\mathrm{u}}$ indicates passengers transferring from $\mathrm{u}^{\text {th }}$ northbound DART to $\mathrm{j}^{\text {th }}$ route

pass $_{\mathrm{j}}^{\mathrm{v}}$ represents passengers transferring from $\mathrm{v}^{\text {th }}$ southbound DART to $\mathrm{j}^{\text {th }}$ route 
pass $_{\mathrm{j}}$ is the total number of passengers transferring to $\mathrm{j}^{\text {th }}$ route

bus $_{j}{ }_{j} \quad$ is the departure of $\mathrm{l}^{\text {th }}$ bus on $\mathrm{j}^{\text {th }}$ route

dart $^{\mathrm{u}} \quad$ represents arrival of $\mathrm{u}^{\text {th }}$ northbound DART

dart ${ }^{\mathrm{v}} \quad$ represents arrival of $\mathrm{v}^{\text {th }}$ southbound DART

$\delta_{\mathrm{j}}^{\mathrm{u} . \mathrm{l}} \quad$ shows whether transfer of passengers is possible. It attains a value of 1 if transfer from $\mathrm{u}^{\text {th }}$ northbound DART to $\mathrm{l}^{\text {th }}$ bus on $\mathrm{j}^{\text {th }}$ route at DART station is feasible; otherwise it attains a value of 0

$\delta_{j}^{v . l} \quad$ shows whether transfer of passengers is possible. It attains a value of 1 if transfer from $\mathrm{v}^{\text {th }}$ southbound DART to $\mathrm{l}^{\text {th }}$ bus on $\mathrm{j}^{\text {th }}$ route at DART station is feasible; otherwise it attains a value of 0

$\mathrm{t}_{\mathrm{inv} \_\mathrm{j}} \quad$ denotes in-vehicle time in bus on $\mathrm{j}^{\text {th }}$ route

$f_{j} \quad$ is the frequency of buses on $j^{\text {th }}$ route in terms of number of bus trips per hour

$1_{j} \quad$ represents length of $j^{\text {th }}$ route in kilometers

$\mathrm{T} \quad$ is time period in hours

$\mathrm{Q}_{\mathrm{j} \text {.max }}$ is the maximum number of passengers on $\mathrm{j}^{\text {th }}$ route for the given time period

CAP indicates bus seating capacity; for Dublin buses it is 74 (Wilson 2000)

$\mathrm{L}_{\max } \quad$ equals the maximum load factor; it is 1.2 for the case study (Wilson 2000)

$\mathrm{L}_{\text {min }} \quad$ equals the minimum load factor; it is 1 for the case study

$\mathrm{d}_{\text {unsat }} \quad$ represents unsatisfied demand

SR equals set of routes

$\mathrm{NB}_{j} \quad$ is the number of buses required in any route $j$

$(R T) j$ is the round-trip time of the bus on $\mathrm{j}^{\text {th }}$ route in minutes $=2 \mathrm{t}_{\mathrm{j}}$ (in minutes) + layover time ( 5 minutes for the case study) 
$\mathrm{t}_{\mathrm{j}} \quad$ represents total travel time on the route in minutes, including stopping times (journey time)

TP equals time period in minutes

$\mathrm{N}_{\mathrm{j}} \quad$ is the number of trips per hour times the time period in hours under consideration $\left(\mathrm{f}_{\mathrm{j}} * \mathrm{~T}\right)$

W denotes the maximum number of available buses

The first two terms of the objective function indicate user cost; the third term denotes operator cost. User cost is the summation of costs associated in transferring from DART services (both north and southbound) to coordinating buses (first term) and the cost of traveling time in the buses (second term). Operator cost is in terms of vehicle operating cost, which is proportional to the distance traveled by buses (third term). Constants $\mathrm{C}_{1}, \mathrm{C}_{2}$, and $\mathrm{C}_{3}$ are used to convert each term of the objective function in monetary unit of Euro $(€)$. The first and second constraints ensure that the load factor lies within a maximum and a minimum value. If the load factor is less than a maximum value, then the crowding level will be less and a better level of service will prevail. The level of service should not be less than a minimum value so as to ascertain availability of a certain minimum number of passengers for economical operations. The maximum load factor is the ratio of crush capacity and normal capacity of Dublin buses. The crush capacity is 88 and normal capacity is 74; thus, the maximum load factor (the ratio of the two capacities) is 1.2 (Wilson 2000). The minimum load factor is 1 . The third constraint is associated with fleet size. This constraint puts an upper limit on the maximum number of available buses for operation. The fourth constraint ensures that maximum demand is satisfied and the maximum number of commuters get coordinating buses during the period of analysis. The aim of schedule coordination is to provide coordinating buses to all commuters who transfer from trains to buses. If a large number of commuters are not able to get coordinating buses, the penalty should be higher and it is added to the objective function so that subsequently the GA search for optimal or near optimal values is directed. The penalty corresponding to the fourth constraint is proportional to the ratio of demand unsatisfied to the capacity of buses. This penalty would have played a more realistic role if data collection was done for the whole day (i.e., until the last DART and last available bus). 
Because the objective function and constraints in the study pose a constraint optimization problem, the penalty method is adopted for optimization (Deb 1995). Using GAs, the minimum value of the penalized objective function is determined (best fit). Routes and frequencies corresponding to this minimum value are optimal feeder routes and frequencies. These optimal frequencies are used to determine coordinated schedules of feeder buses.

Fitness function $=$ Minimize (Objective Function + Penalties 1 to 4$)$

Penalty 1: If load factor is more than a maximum value (1.2 for the case study)

Penalty 2: If load factor is less than minimum value ( 1 for the case study)

Penalty 3: If fleet size exceeds a minimum value ( 25 for the case study)

Penalty 4: If some demand remains unsatisfied

It is also observed in our typical traffic surveys that it takes about 5 minutes for commuters to reach bus stops located outside the station after arriving from DARTs. Thus, transfer from DART to a bus is feasible if the bus departs only after 5 minutes of scheduled arrival of the DART.

\section{Step 6}

Find out the percentage of demand satisfied by increasing/decreasing/changing the destinations as discussed in steps 4 and 5. Initially a few nodes (destinations identified in traffic surveys) that are well scattered and away from the origin are selected. $\mathrm{K}$-paths are developed and it is determined how much the percentage of demand remains unsatisfied after application of GAs. The additional destination is added and again any improvement in satisfaction of percentage demand is determined. The number of destinations for which the maximum demand is satisfied is selected. By gradually augmenting the number of destinations, the maximum possible demand satisfaction is achieved. The minimum number of destinations leading to the maximum satisfaction of demand is selected as potential destinations. If the entire demand is satisfied for a particular combination of potential destinations, then the corresponding feeder routes and frequencies (for determination of coordinated schedules) are optimum. If the entire demand is not satisfied, go to step 7.

\section{Step7}

Find the nodes leading to unsatisfied demand and insert them in the developed feeder routes by a heuristic node selection and insertion process. The node selec- 
tion and insertion process acts as repair heuristics by modifying routes. [For a detailed discussion on node selection and insertion process/strategies, see Shrivastava and Dhingra (2001).] Using these repair heuristics, the following innovative ways can be employed for development of feeder routes:

- Determination of the best path among others in which an identified node (destination) can be inserted. The path is selected based on savings in passenger walk time and an increase in bus passenger time due to insertion of a node.

- After selecting the best path, the best way of insertion of node is identified. The best way is the one that gives least delay to destinations following the inserted node.

\section{Step 8}

Once all the nodes are inserted, the developed routes are used for determination of frequencies using GAs leading to optimum coordinated schedules for the existing DART schedules.

The objective function for this stage is simpler than the one discussed in step 5 . In step 5 both routes and frequencies are determined using GA, whereas in this step only frequencies are determined. Therefore, the objective function involves only the first term (transfer time between DARTs and buses) and third term (vehicle operating cost) along with all the constraints of step 5 . In step 5 the routes and frequencies were coded together, whereas in this step only frequencies are coded. Thus, the analysis at this stage is simpler than the one discussed in step 5 . In view of this, the details of application of GA are not discussed here. [For a detailed discussion on determination of coordinated schedules on fully developed feeder route network, see Shrivastava and Dhingra (2002)].

Use of GAs for Objective Function and Constraints. GAs are based on exhaustive and random search techniques that are found to be robust for optimizing nonlinear and nonconvex functions (Holland 1992). In this research generational GAs with reproduction, crossover, and mutation operators are used (Goldberg 1989). The penalty method of constrained optimization is adopted (Deb 1995).

The proposed objective function is used with LibGA software of GAs in Linux environments to determine optimal frequencies on the developed feeder route network (Chambers 1995). GA parameters are tuned for the objective function and this type of process and best values of operators are decided. Roulette selection, simple random mutation, and uniform crossover are adopted. With seed 
value as 1 , pool size 30 , crossover probability 0.85 , and mutation probability 0.005 , the lowest value of penalized objective function (objective function plus penalties) is provided. These values are used for the analysis. A set of frequencies on various routes corresponding to the minimum value of the penalized objective function is used for determining coordinated schedules on various routes.

The decision variables are routes and frequencies of buses during the application of GA. Routes and frequencies are coded together in the same string. The most common coding method is to transform the variables to a binary string. GA performs best when binary coding is adopted (Goldberg 1989). The length of the string is determined as per the desired solution accuracy. In this study, routes and coordinating frequencies of each pair are coded into a single string. Figure 2 indicates typical binary digits coding for routes 5 and 3 with frequencies 6 and 21 per hour. The first four bits show the route and the last six bits show the corresponding frequency in a string.

\section{Figure 2. Binary Digit Coding}

\begin{tabular}{|c|c|c|c|c|c|c|c|c|c|c|c|c|c|c|c|c|c|c|c|}
\hline \multicolumn{9}{|c|}{ Pair No. 1 } & \multicolumn{1}{c|}{ Pair No. 2 } \\
\hline \multicolumn{3}{|c|}{ Route } & \multicolumn{3}{c|}{ Frequency } & \multicolumn{3}{c|}{ Route } & \multicolumn{7}{c|}{ Frequency } \\
\hline 0 & 1 & 0 & 1 & 0 & 0 & 0 & 1 & 1 & 0 & 0 & 0 & 1 & 1 & 0 & 1 & 0 & 1 & 0 & 1 \\
\hline \multicolumn{3}{|c|}{ Route 5 } & \multicolumn{3}{|c|}{ Frequency 6 } & \multicolumn{3}{|c|}{ Route 3 } & \multicolumn{7}{c|}{ Frequency 21 } \\
\hline
\end{tabular}

The search space depends on the pool size and smaller pool sizes take less computational time. The case study discussed in this article requires much lower computational time because the size of matrix is very small. In the case of a large network and matrix, the pool size can be appropriately chosen based on convergence criterion. If a smaller pool size is taken, computational time will be lower and values closer to optimal can be obtained. Such values are practically acceptable for this type of problem. However, such smaller pool sizes should be tested with other operators and parameters for a given problem. The heuristic part of the algorithm does not take much computational time because only a few nodes are to be inserted on a fully developed network. 


\section{Results and Discussion}

As discussed in the methodology, well-scattered minimum destinations satisfying maximum demand are selected as potential destinations. Maximum demand is satisfied when nodes $11,12,13,15$, and 16 are selected as potential destinations. Only 2.95 percent of demand remains unsatisfied for which the heuristic node selection and insertion strategy is applied. Table 2 lists the routes developed along with frequencies (for schedules) after application of GAs.

\section{Table 2. Routes and Frequencies after Application of GAs}

\begin{tabular}{clc} 
S. No. & Nodes in Feeder Routes & Length (in km) \\
\hline 1 & $1-3-11$ & 4.5 \\
2 & $1-2-3-17-12$ & 6.75 \\
3 & $1-4-6-7-13$ & 8.00 \\
4 & $1-6-7-8-15$ & 10.25 \\
5 & $1-2-5-10-9-16$ & 9.00
\end{tabular}

Since the developed feeder route network does not satisfy 100 percent demand due to the absence of destination node 14 in the structure of feeder routes, the next stage of further modification of feeder routes using node selection and insertion strategies is adopted. Nodes are inserted/attached to developed feeder routes. Frequencies associated with feeder routes in the earlier stage are discarded since fresh frequencies are required to be determined due to modification of routes. After applying a heuristic node selection and insertion process, node 14 is attached with the third route and the length of the third route increases from 8 $\mathrm{km}$ to $9.68 \mathrm{~km}$. Figure 3 shows the finally developed five-feeder route. Routes 3 and 4 partially overlap; also node 3 is common to routes 1 and 2 . Thus, the overlapping aspects of routes are also successfully attempted in this research. The connectivity between 13 and 14 could be established by repair heuristic. Node 14 was not included in the approach of Shrivastava and O'Mahony (2006) as its demand was not satisfied by the approach adopted and was omitted.

In the development of routes, the origin (DART station) remains the same for all destinations. Therefore, all feeder routes originate from the DART station only. It looks very similar to the spanning tree rooted at DART station (Figure 3). However, the best alternative path out of the selected k-paths for each origin and destina- 


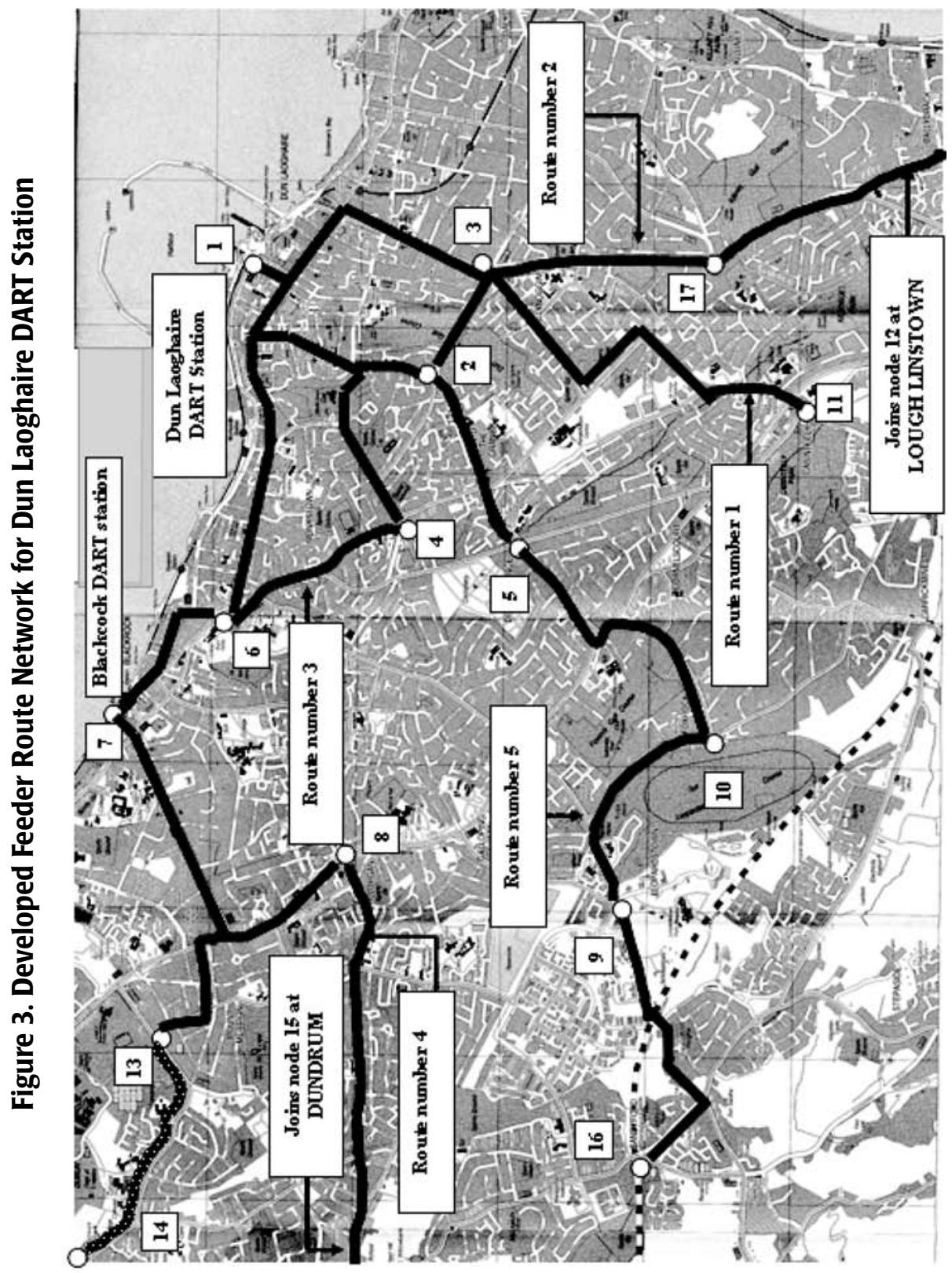


tion set is developed by a combination of the GA and heuristic approach. In some of the earlier approaches, links on the spanning tree are added/removed to achieve the best network. The approach adopted in this research is quite different.

Table 3 indicates coordinated schedules of feeder buses for the existing schedules of DART and the average load factors on each route. As shown in the table, the load factor varies in the range of 0.33 to 0.83 . These load factors will further improve due to local demands at en-route stops. Local demand is not considered because the routes are designed for feeder buses from the DART station. Hence, demand satisfaction generating from the DART station is of prime concern.

The overall load factor attains a value of $0.58-$ a much improved value against the present scenario in which the load factor remains in the range of 0.2 to 0.3 even during peak hours. Feeder routes and coordinated schedules for the same study area were developed by decomposing the problem in two stages: one for development of feeder routes using the heuristic approach only and another for schedule coordination with GAs (Shrivastava and O'Mahony 2005). Load factors for different routes were in the range of 0.16 to 0.45 with an overall load factor of 0.36 . Thus, load factors and the overall load factor by the proposed model have improved values. A comparison between the existing scenario and improvements due to the proposed model is given in Table 4. If all the routes are viewed together, then 42 percent of demand is satisfied within 5 minutes of effective waiting and 29 percent is satisfied between 6 to 10 minutes of waiting. More than 70 percent of demand is satisfied within 10 minutes of effective waiting. The entire demand is satisfied within 20 minutes of effective waiting. In the present scenario, the majority of commuters wait 20 minutes or more for buses and the load factor is also less than 0.3 most of the time even during peak hours. Route details show that on route 2,62 percent of demand is satisfied within 5 minutes and the entire demand is satisfied within 10 minutes of effective waiting. Route 2 carries about 31 percent of the total trips, making it the maximum trip carrier.

On all routes more than 50 percent of demand is satisfied within 10 minutes of effective waiting. In the developed feeder route structure, route lengths vary between $4.5 \mathrm{~km}$ to $10.25 \mathrm{~km}$ and 100 percent demand is satisfied without any transfer. If a similar exercise is carried out by identifying influence areas of all stations, shorter feeder routes with better schedules will be developed (Shrivastava and Dhingra 2001). This is due to the fact that one node may be connected to more than one DART station and its connectivity will certainly be better with shorter connecting lengths from one particular station only. As shown in Figure 3, 


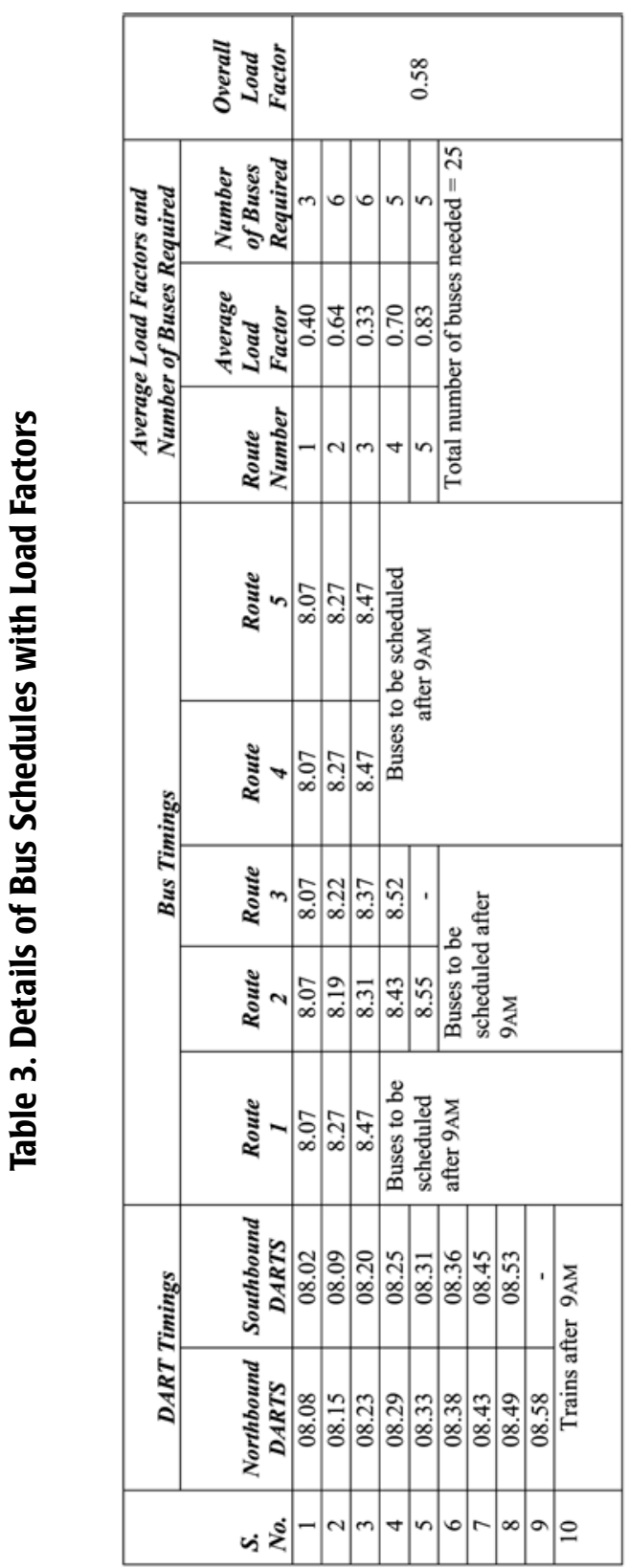




\section{Table 4. Comparison between Existing and Proposed Route Network}

\begin{tabular}{|l|l|l|}
\hline \multicolumn{1}{|c|}{ Property for Comparison } & \multicolumn{1}{|c|}{$\begin{array}{c}\text { Existing Route Network in } \\
\text { Study Area }\end{array}$} & $\begin{array}{l}\text { Proposed Route Network for } \\
\text { Study Area }\end{array}$ \\
\hline Type of route network & Not a feeder route network & Feeder route network \\
\hline Average load factor on routes & Less than 0.3 & $\begin{array}{l}\text { Overall load factor is } 0.58 \text { and } \\
\text { is greater than } 0.3 \text { on all routes }\end{array}$ \\
\hline $\begin{array}{l}\text { Waiting time/percentage } \\
\text { demand satisfaction }\end{array}$ & $\begin{array}{l}\text { Average waiting time is more } \\
\text { than } 20 \text { minutes }\end{array}$ & $\begin{array}{l}42 \% \text { of demand is satisfied } \\
\text { within } 5 \text { minutes, } 71 \% \text { within } \\
10 \text { minutes, and } 100 \% \text { within } \\
20 \text { minutes of effective } \\
\text { waiting }\end{array}$ \\
\hline
\end{tabular}

destinations like Stillorgan (code 8), Mount Merrion (code 13), University College Dublin (code 14), and Dundrum (code 15) are closer to Blackrock DART station as compared to Dun Laoghaire. Feeder routes for these destinations from Blackrock will be shorter.

The modelling exercise was carried out only for the morning peak hour. The frequency of buses will change during other hours of the day as per the demand. In fact traffic surveys should be conducted for the whole day, covering both peak and off-peak hours. The same methodology can be implemented to determine coordinated schedules of public buses during different periods of the day. A whole day travel pattern will provide more realistic demand to different destinations for development of feeder routes, schedules, and optimum fleet size for different periods of the day.

\section{Conclusions}

In the proposed model, well-scattered destinations from the DART station satisfying maximum demand were selected as potential destinations. Feeder routes and frequencies leading to coordinated schedules were developed simultaneously from the DART station to selected potential destinations using GAs. As a low number of potential destinations is found with maximum demand satisfied, the number of generated routes are less. The selection of minimum destinations leads to a low number of routes. If demand at some destinations remains unsatisfied, then with the help of the heuristic algorithm, which works as a repair algorithm, such destinations are inserted/added to the developed feeder route structure. After modification of the route structure, GAs are again applied to determine 
modified coordinated schedules. The following conclusions can be derived from the proposed modelling exercise:

1. In the proposed modelling exercise the optimized feeder routes and coordinated schedules are developed together in the first phase. Most of the routes are developed along with the coordinated schedules in this phase only. The coordinated schedules are further checked with a second application of GAs. In the proposed modelling approach, most of the schedules and routes are complementary to each other.

2. The model strikes a balance between user needs and operator requirements. The objective function incorporates user costs in terms of time spent in buses and transfer time between DARTs and buses; operator cost is vehicle operation cost, which is directly proportional to distance travelled by buses. Similarly, constraints are also applied to cover the requirements of users and operators. The load factor constraint is kept within minimum and maximum values so as to maintain a better level of service for users and economic operation to satisfy operators. The fleet size constraint is also a realistic constraint from the operators' point of view. The constraint for unsatisfied demand increases the probability of availability of seats to commuters though it is not very important when the load factor remains less than a minimum value as has been experienced in the study area.

3. The selection of nodes as potential destinations plays a very important role for successful development of feeder routes for typical destinations in the study area network. The network considered for analysis has nodes well scattered in the influence area and destinations having higher demands are closer to the origin (DART station). Some of the destinations away from the DART station have limited connectivity with other nodes. Selection of potential destinations away from the origin and well dispersed in the influence area develops feeder route structures, which satisfy the maximum demand without any transfer.

4. The influence area of each station can be identified and the modelling exercise can be repeated with large-scale data collection for an entire day. Thus, a fully integrated system can be developed in which DARTs can work as a main line haul facility and buses can feed the local areas. The coordinated schedules of buses can be found for each period of the day and hence their requirement can be determined for peak and off-peak periods. The proposed methodology designs feeder routes without any further transfers and the 
entire demand is satisfied directly from the DART station. The model takes into account the overlapping aspect of different routes successfully.

5. On average, the developed model satisfies more than 50 percent of demand within 10 minutes of waiting time and the entire demand is satisfied within 20 minutes of waiting time with an overall load factor of more than 50 percent. On some routes, 80 to 90 percent of demand is satisfied within 10 minutes of waiting and many routes have load factors even more than 0.7 . In the present scenario (not optimized), the load factor hardly attains a value more than 0.3 and the average waiting time is in the range of 20 minutes or more. Thus, the proposed model judiciously balances waiting time and load factors for feeder buses.

6. The research problem attempted is solely on the development of feeder routes and not a usual network design problem. GA has been successfully implemented for the more usual network design problems where transfer from one route to another is permitted (i.e., passengers are assumed to transfer from one bus to another). In the design of feeder routes, it is not appropriate to incorporate additional transfers on routes because passengers are already subjected to a transfer from train to bus. Therefore, additional transfers will lead to inferior design of the feeder route network. The application of repair heuristics adds to development of feeder routes without additional transfers.

The proposed model can be implemented for the development of feeder routes and coordinated schedules to any other study area if demands to various destinations and network connectivity details are known. Fully optimized feeder routes would be developed if higher demand nodes are well scattered and away from the DART/railway station by the GA itself, otherwise repair heuristics will modify the feeder routes developed by GA. Moreover, feeder routes without additional transfers are desired by planners. Other factors like transfer time, load factors in buses, fleet size, vehicle operating cost, and availability of buses to all commuters are duly taken care both from the users' and operators' point of view. The developed model can be of specific use to service planners working for coordinated operations of public transport modes. 


\section{References}

Agrawal, J., and T. V. Mathew. 2004. Transit route network design using parallel genetic algorithms. Journal of Computing in Civil Engineering 18: 248-256.

Baaj M. H., and H. S. Mahmassani. 1995. Hybrid route generation heuristic algorithm for the design of transit networks. Transportation Research C 3, 1: $31-50$.

Chien Steven I-Jy, B. V. Dimitrijevic, and L. N. Spasovic. 2003. Optimization of bus route planning in urban commuter networks. Journal of Public Transportation 6: 53-80.

Deb, K. 1995. Optimization for engineering design-Algorithms and examples. New Delhi, India: Prentice Hall, 290-320.

Dublin Street Map. 2000. Ordinance Survey of Ireland, 17th ed.

Dubois D., G. Bel, and M. Llibre. 1979. A set of methods in transportation network synthesis and analysis. Journal of Operation Research Society 30, 9: 797-808.

Eppstein, D. 1994. Finding the $k$ shortest paths. Tech. Report 94-26. Department of Information and Computer Science, University of California. http://www.ics. uci.edu/ eppstein/pubs/Epp-TR-94-26.pdf. Accessed September 25, 2004.

Fan, W., and R. B. Machemehl. 2004. Optimal transit route network design problem: Algorithms, implementations, and numerical results. Report number SWUTC/04/167244-1. Center for Transportation Research, University of Texas at Austin.

Goldberg, D.E. 1989. Genetic algorithm in search, optimization and machine learning. Reading, MA: Addison-Wesley Publishing Co.

Gundaliya P. J., P. Shrivastava, and S. L. Dhingra. 2000. Model for simultaneous routing and scheduling using genetic algorithm. Transporti Europei, Quarterly Journal of Transport Law, Economics and Engineering VI, 16: 10-19.

Holland, J. H. 1992. Adoption in natural and artificial systems, 2nd ed. Cambridge, MA: MIT Press.

Lampkin, W., and P.D. Saalmans. 1967. The design of routes, service frequencies and schedules for a municipal bus undertaking: A case study. Operation Research Quarterly 18, 4: 375-397. 
Chambers, L. 1995. Practical Handbook of Genetic Algorithms Applications, Vol. I. CRC Press.

Mandl, C. E. 1980. Evaluation and optimization of urban public transport networks. European Journal of Operational Research. 6: 31-56.

Pattnaik S. B., S. Mohan, and V. M. Tom. 1998. Urban bus transit route network design using genetic algorithm. Journal of Transportation Engineering 124, 4: 368-375.

Shrivastava, Prabhat and S. L. Dhingra. 2001. Development of feeder routes for suburban railway stations using heuristic approach. Journal of Transportation Engineering 127, 4: 334-341.

Shrivastava, P., and S. L. Dhingra. 2002. Development of co-coordinated schedules using genetic algorithms. Journal of Transportation Engineering 128, 1: 89-96.

Shrivastava, P., and M. O'Mahony. 2005. Modeling an integrated public transport system-A case study in Dublin, Ireland. Submitted to Transportation Research-An international journal published by Elsevier Science.

Shrivastava, P., and M. O'Mahony. 2006. A model for development of optimized feeder routes and coordinated schedules-A genetic algorithms approach. Transport Policy 13, 5: 413-425.

Silman L. A., Z. Brazily, and U. Passy. 1974. Planning the rout system for urban buses. Computer and Operation Research 1: 201-211.

Steer Davies Gleave. 1994. Dublin transportation initiative, final report and technical reports. Dublin: Stationery Office.

Tom V. M., and S. Mohan. 2003. Transit route network design using frequency coded genetic algorithm. Journal of Transportation Engineering 129, 2: 186195.

Wilson, S. 2000. Final Report on Bus Network Strategy Appraisal Report for Greater Dublin Area. www.dublinbus.ie/about_us/pdf/swilson.pdf. Accessed May 13, 2004.

Zhao, H., and I. Ubaka. 2004. Transit network optimization-minimizing transfers and optimizing route directness. Journal of Public Transportation 7:67-82. 


\section{About the Authors}

Prabhat Shrivastava (prabhat_shri@vsnl.net) is an assistant professor of traffic and transportation planning in the Department of Civil Engineering at Sardar Patel College of Engineering at the University of Mumbai, India. Dr. Shrivastava was a research fellow at the Centre for Transportation Research, Trinity College, University of Dublin, Ireland, from March 2004 to June 2005. His primary degree is in civil engineering. He earned his master of technology in transportation planning from the Indian Institute of Technology, Madras (Chennai), and Ph.D. in intermodal coordination from the Indian Institute of Technology, Bombay (Mumbai). Dr. Shrivastava has been involved in teaching, research, and consultancy assignments related to traffic and transportation planning for the last 15 years. His research interests are integration of transport modes, routing and scheduling problems, simulation modeling, and applications of advanced techniques for transportation modeling.

MARGARET O'MAHONY (margaret.omahony@tcd.ie) is an associate professor and head of the Civil, Structural, and Environmental Engineering Department at Trinity College. Prof. O'Mahony has worked in transport research for 20 years. She is widely published and has interests in public transport, transport modelling, the environmental impacts of transportation and freight transport. 